\title{
Sounding the Alarm: Six Strategies for Medical Students to Champion Anti-Racism Advocacy
}

This article was published in the following Dove Press journal:

Journal of Healthcare Leadership

\section{Deborah Fadoju',* \\ Rosevine A Azap',* \\ J Nwando Olayiwola (D) ${ }^{2}$ \\ 'The Ohio State University College of Medicine, Columbus, OH, USA; \\ ${ }^{2}$ Department of Family and Community Medicine, The Ohio State University College of Medicine, Columbus, $\mathrm{OH}$, USA}

*These authors contributed equally to this work

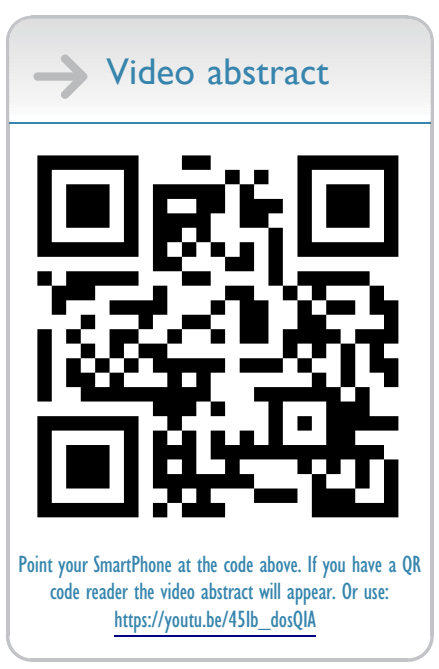

Correspondence: J Nwando Olayiwola Email Nwando.Olayiwola@osumc.edu

\begin{abstract}
Every year, incoming medical students take the Hippocratic Oath and pledge that they: "will be an advocate for patients in need and strive for justice in the care of the sick," yet guidance on how to engage in community and public health advocacy is not a mandatory component of medical education. Therefore, students often feel insufficiently qualified to engage in advocacy efforts. As the nation has struggled with a viral pandemic (COVID-19) and witnessed an uprising against anti-Black racism and police brutality, it became immediately apparent that activism that marries medicine to anti-racism advocacy was needed. Further, we deduced that anti-racism activism at medical institutions would need to position medical students, often low in the medical hierarchy, as essential to the response. With the support of our leaders and mentors, we created a concerted series of strategies for medical students to become front and center in advocacy efforts. In this paper, we outline six strategies for medical students across the nation to champion anti-racism advocacy, based on our successful experiences in Central Ohio. This approach may have utility for other medical schools across the nation. These strategies include: embracing a common agenda; establishing formal structures; engaging affinity groups and allies; endorsing legislative advocacy; encouraging curricular reform; and enriching the pipeline. It is our hope that medical students will feel empowered and activated to lead and organize "good trouble" efforts that will ultimately improve the lives and health of the communities and patients they are being trained to serve.
\end{abstract}

Keywords: racism, anti-racism, advocacy, medical education, community organizing, health equity

Studying while the world is in chaos has been trying. We all know the famous adage, "medical school is a marathon." For many, it has felt more like an uphill battle than an equitable race. If it was not COVID-19 disproportionately killing Black and Brown communities, it was helplessly watching the continued inhumane treatment of Black people across the nation. ${ }^{1-3}$ Along the course, we have been longing for justice that we only hope will come. But, sometimes we wonder, how are we expected to run if we cannot breathe?

The nation is currently experiencing an uprising against systemic anti-Black racism and police brutality, as well as a reckoning that racism is a social determinant of health, contributing to poor and disparate health outcomes for minoritized populations. But, in order for this present outrage to emerge, the circumstances had to be dire - a novel virus leading to the COVID-19 pandemic, a tragic murder in a video seen all over the world. However, the design of the current medical education model is one in which curriculum and community engagement are divorced. Every year, incoming medical students take the Hippocratic Oath and 
pledge that they "will be an advocate for patients in need and strive for justice in the care of the sick," yet guidance on how to engage in community and public health advocacy is not a mandatory component of medical education. Therefore, students often feel insufficiently qualified to engage in advocacy efforts. Moreover, now, what has become necessary is a sort of activism that marries medicine to anti-racism advocacy, and positions medical students, lower in the medical hierarchy, as essential to the response. Our lived experiences, as two Black medical students and one Black faculty member, including our own share of racist experiences in medicine and the personal weight of a pandemic that disproportionately affects Black and Brown communities, provided the ultimate push to drive action within our institution.

At this moment in our nation's history, medical student activism can be, in the words of the late Congressman John Lewis, "good trouble," and push the field to become more daring. Student activism can push the profession to be one that dares to solve problems not directly within its purview, but also problems that expand far beyond the reach of hospital beds or operating rooms and into the deep spaces of social reform. In the development of a framework for community organizing, Marshall Ganz, internationally renowned for his expertise in social justice, described the core practices of social movements and advocacy to include factors such as commitment, creative strategizing, and channeling of collective resources. ${ }^{4}$ In particular, the Ganz model calls for relationship building at the foundation of social movement organizations and identifying stakeholders, while utilizing storytelling as a form of communication to facilitate purposeful action. ${ }^{4}$ Moreover, the Ganz model describes time as an "arrow framework" to show that the timeline of any social movement depends on the various objectives achieved on the pathway to making change. ${ }^{4}$

We found these core principles of social movements to be necessary for the successful implementation and sustainment of student-led anti-racism programs at medical institutions. To this point, as the leaders of student organizations at our institution, Student National Medical Association (SNMA) and Health Education and Development Services for Underprivileged Populations (HEADS UP), we applied the Ganz model of community organizing and called on our organizations to champion racial justice efforts. Over the past few months, we have translated that power into six strategies (Figure 1) that medical students can engage in to pursue racial justice, immediately and effectively. We hope that medical students in other settings will find utility in this approach. This perspective paper did not require IRB approval as it was not research.

\section{Six Strategies \\ Embrace a Common Agenda}

In order to move towards concrete solutions in the Ganz framework, it is critically important to first identify that there is a problem and align on a shared agenda within the institution. This alignment cannot happen without candid conversations that lay bare the reality of racism. In moments like this, it is important to move away from generic responses that make mention of standing in solidarity, but fail to use the word "racism" and "police brutality."

Our first order of business was to create a space for an open conversation between trainees and faculty in a virtual event led by medical students entitled "Can We Talk?: A Conversation on Race, Racism, and Public Health." The goals of this event were to: (1) Create an emotional outlet for attendees in the wake of George Floyd's tragic murder and (2) Advocate for a shared agenda that would result in new anti-racism policies to elevate our institution's commitment to racial equity. During this conversation, students, faculty, and leadership came to a common understanding that racism is a prevailing problem in our society. We, as a community, agreed to embrace an agenda to eradicate racial inequity.

\section{Establish a Formal Structure}

After realizing that many individuals were seeking ways to join in anti-racism efforts, we recognized the need to formally organize. Accordingly, SNMA partnered with student leaders from Physicians Action Network (PAN) and formalized a coalition in alignment with others across the nation: a new chapter of White Coats for Black Lives (WC4BL). Creating a connection platform, with rules of etiquette, expectations and structure allowed many student groups to channel information to their peers. The coalition communicated through a student organized GroupMe, a messaging platform for connecting large groups of people and sharing text, photos, calendar invitations, documents and more, regardless of phone operating systems. Each day, using this platform, student leaders in the coalition created a "Call to Action"-outlining specific items students could do, from calling a local 


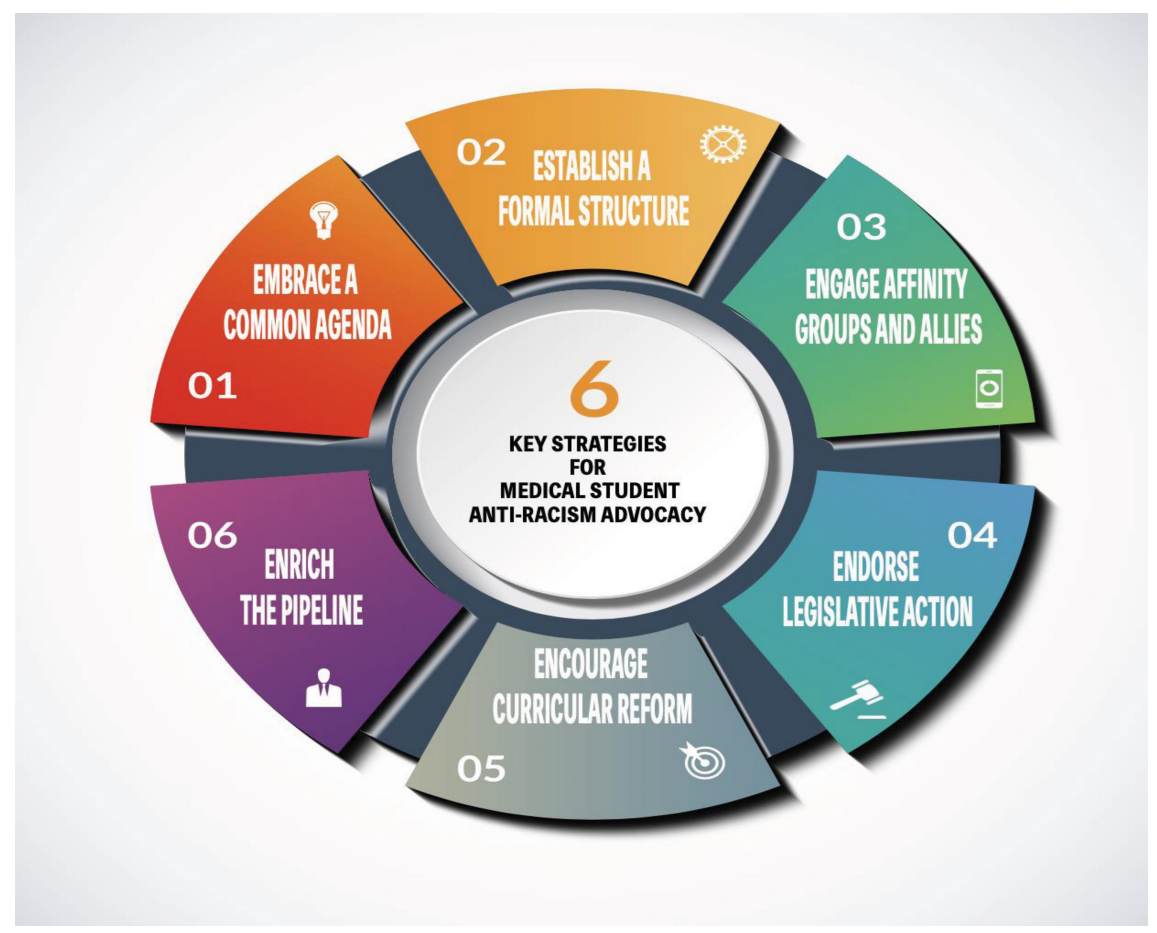

Figure I Framework for anti-racism key strategies. This framework provides 6 key strategies that medical students can use to engage in anti-racism advocacy at their medical institution and in the community. Source: Fadoju, Azap and Olayiwola.

government official to attending a peaceful protest in their area. The platform allowed for real-time communication and engagement. Medical students across the nation can employ this strategy by forming coalitions focused on anti-racism and diversity efforts and leveraging technology and other tools to organize them. The key, however, to successful implementation of this strategy is to employ a trusted forum of accountability that encourages members to confirm completion of action items and activities.

\section{Engage Affinity Groups and Allies}

Additionally, we hosted events that brought affinity communities together to publicly denounce systemic racism. We led a \#WhiteCoats4BlackLives demonstration at our medical institution, along with resident physicians representing Graduate Medical Education (GME). Over 500 healthcare workers, students, local leaders, and public officials gathered on the lawn of the James Cancer Hospital. We kneeled in solidarity for 8 minutes and 46 seconds to commemorate George Floyd's final moments.

We then collaborated with other allies and affinity groups, including PAN, to host a solidarity march to the Ohio Statehouse, where medical personnel donned their white coats and spoke out about racism as a public health crisis. These demonstrations allowed people to use the privilege and power afforded to them by their professional position to provoke change, and in turn, applied the Ganz model of effective storytelling for communal change. Additionally, we organized an interdisciplinary, crossinstitutional Diversity, Equity, and Inclusion Week in partnership with other student organizations at our medical institution: HEADS UP, SNMA, Student Council, LGBTQ+ and Allies in Medicine, Students for a National Health Program, and Gold Humanism Honor Society. This week featured over 15 lectures, workshops, and events led by experts on topics, such as microaggression and implicit bias, the roots of racism and segregation, the school to prison pipeline, and community engagement to achieve health equity. Never in our College of Medicine's history have students pioneered such a landmark series of events forcing attention to these important topics. We believe that medical students can similarly pioneer change at their institutions through public demonstrations and events that seek to educate those in their communities about the importance of diversity, equity, and inclusion.

\section{Endorse Legislative Action}

Due to the importance of legislative action and inaction in perpetuating racial, social and economic inequities, 
legislative reform is crucial to undoing the tragic effects of racism. However, students are rarely given the opportunity to influence it.

In June 2020, our medical students received notice of a formal hearing on the Ohio Senate Concurrent Resolution 14, a resolution to declare racism a public health crisis. ${ }^{5}$ Employing our newly chartered WC4BL chapter, we immediately and effectively mobilized our medical student body to endorse the legislation through providing testimony, something many had never done. Many students were initially intimidated by the thought of this sort of civic engagement, but we supported one another in helping to shape and provide authentic perspectives, citing personal narratives, research data, and literature. Behind every student who submitted a testimony were countless students that helped to edit and review them. Additionally, 11 brave medical students delivered oral testimonies in front of members of the Ohio Senate in a remarkable display of legislative advocacy, channeling collective resources as a central element of the Ganz framework. As of December 1, 2020, this resolution has been referred to the Senate Health, Human Services and Medicaid Committee and is currently pending in the Ohio General Assembly. These efforts of medical students at our institution can be replicated across the nation. Medical students at various institutions can seek opportunities to testify in front of their local government officials. Furthermore, medical students can engage in legislative advocacy training workshops where they are equipped with tools to effectively advocate for the most vulnerable members of our society. Through acts of legislative practice, medical students have the power to impact policies with broad implications in their society.

\section{Encourage Curricular Reform}

Traditionally, education of medical students has focused on the treatment of medical ailments with little emphasis on how the social determinants of health-racism, discrimination, and stress - influence health outcomes. Ensuring that medical students become physicians who are committed to mitigating the negative effects of racism would require radical reform of our medical curricula's portrayal of race and racism with strategic ingraining of anti-racism teaching.

Our chapter of SNMA knew it was important to collect tangible data that reflected the perspectives of underrepresented minority (URM) students at our institution. We administered a 15-minute, 36-question survey to collect these perspectives, and received over 10 pages of recommendations. Of note, medical students called for massive curricular reform, such as: formally teaching the historical context of medical mistreatment of minorities, dispelling race-based medical misconceptions, removing false biologic constructs of race, and teaching the true implications of racism on healthcare. We provided the recommendations to our medical school's leadership team and a number of our SNMA members have been asked to participate in task forces created specifically for curricular overhaul. As stakeholders, it is vital that we contribute to improving medical education. Medical students should not be passive partakers, but rather, critical evaluators of their own medical education. Students should call attention to ways in which professors can incorporate social determinants of health, social justice advocacy, and health equity to medical education.

\section{Enrich the Pipeline}

Finally, we recognize that though medical students are only at the beginning of the journey to becoming physicians, medical students still have a duty. We must use our privilege and position to ensure that our efforts and interventions begin far earlier in the pipeline. We have a responsibility to clear the path and create opportunities for underrepresented youth to pursue careers in medicine.

During this period, we recognized the importance of role modeling and structurally improving the experiences of children in our local communities. Given that the distortion of Black history and the educational recycling of racist rhetoric begins in the earliest moments of childhood, HEADS UP developed a virtual 7-week summer curriculum that provided underserved youth with education on African-American contributions to the United States, health professions exposure, mental health and wellbeing, pandemic realities, racism and identity, as well as mentorship from medical student and undergraduate student volunteers. Furthermore, HEADS UP recognized the need to engage with students of various ages across the education spectrum and initiated a meeting with the leaders of Columbus City Schools (CCS), the largest school district in the State of Ohio, to be a thought partner in our planned reform of Black imagery in education. In the development of a highschool mentorship program, HEADS UP received a Research!America grant to expand mentoring and community partnerships within the CCS system, in partnership with the OSU Department of Surgery. Other medical students can work towards social 
equity by serving as mentors to the youth in their communities and partnering with local school districts who are working to make lasting change. Students can engage in these efforts by creating or partnering on pipeline programs alongside their local school district, and hosting mentorship events with pre-medical students on nearby college campuses.

\section{Conclusion}

Our efforts to examine and achieve equity through an antiracist lens are far from complete, and yet concrete change is already visible. The anti-racism initiatives and programs pioneered by medical students were vital to numerous institution-wide conversations surrounding diversity, equity, and inclusion. These student led efforts allowed for leadership at the medical center, including the Chancellor, Deans and others, to commit to supporting and elevating this cause, while providing resources towards anti-racism activities. In fact, some of this work has been foundational as our medical center started taking steps to make anti-racism a core value. ${ }^{6}$ Furthermore, the integration of students into the institution-wide programming allowed for diversity and versatility in initiatives. Many of the contributions students made have been integrated into the institution-level anti-racism action plan initiatives for the medical center and health sciences colleges through an impact on policy, advocacy, and training. Finally, our efforts have resulted in a newly formed coalition, "Black Women in Medicine," designed to create fellowship, mentoring, collective impact and safe spaces for Black Women students, trainees, staff, leaders, and faculty across the institution to network and support one another. This group is already leveraging the Ganz principle of storytelling for impact and change.

We believe that similar applications of the Ganz social movement framework by medical students across the nation will be of great importance and but also great impact—not just for educational purposes, but as a way to prepare and empower young professionals who will be ultimately charged with creating equitable healthcare opportunities for all members of society. In many ways, the translation of student led efforts into significant changes at medical institutions can be of great value.

The problem of systemic anti-Black racism is deeply embedded into our society. Therefore, the solutions we raise must be overt and blatant. Through the application of the Ganz framework, we learned how integral it is for medical students to formalize social movement efforts in order to create sustainable impact at their institutions. We feel proud that this work is becoming a part of the values of our institution and it gives us great hope for our futures. However, the work to achieve racial equity and to face racism as a public health crisis cannot fall subject to the "minority tax," in which people from underrepresented backgrounds are responsible for fighting for change that has oppressed or marginalized them. Our institution and other academic medical centers will need to ensure that anti-racism efforts are part of their core values ${ }^{6}$ and that the labor is spread among many, including non-minoritized stakeholders.

As medical students, we may not know how to perform complicated lifesaving trauma surgeries or manage the polypharmacy of patients with multiple chronic comorbidities - but, we are still called to save lives. Right now, the nation is sounding the alarm that racism is a leading cause of death for too many marginalized lives. In this battle to uproot systemic racism, there is no need for silent spectators. As the most junior members of the medical workforce, it is imperative that we, as medical students, find our footing to lead "good trouble" efforts, and engage in advocacy efforts for patients beyond the clinical setting, while pushing our institutions to make direct and sustainable change. We believe that the six strategies we have shared can be applied by medical students across the nation as they champion anti-racism advocacy in their own environments. At this very moment, there is a communal call to action-we hope students across the nation will answer and believe that they are well positioned to do so.

\section{Disclosure}

The authors report no conflicts of interest in this work.

\section{References}

1. Dyer O. Covid-19: black people and other minorities are hardest hit in US. BMJ. 2020;m1483. doi:10.1136/bmj.m1483

2. Yancy CW. COVID-19 and African Americans. JAMA. 2020;323 (19):1891. doi:10.1001/jama.2020.6548

3. Thebault R, Tran A, Williams V The coronavirus is infecting and killing black Americans at an alarmingly high rate [Internet]. The Washington Post; 2020. Available from: https://www.washingtonpost. com/nation/2020/04/07/coronavirus-is-infecting-killing-blackamericans-an-alarmingly-high-rate-post-analysis-shows/?arc404=true. Accessed December 24, 2020.

4. Ganz M Leading change: leadership, organization, and social movements. 21 . 
5. Hoagland F, Bacon K, Balderson T, et al. Senate concurrent resolution 14 [Internet]. Ohio Legislature. Available from: https://www.legisla ture.ohio.gov/legislation/legislation-summary?id=GA132-SCR-14. Accessed December 24, 2020.
6. Olayiwola JN, Joseph JJ, Glover AR, Paz HL, Gray DM. Making anti-racism a core value in academic medicine. Health Aff. 2020. doi:10.1377/hblog20200820.931674

\section{Publish your work in this journal}

The Journal of Healthcare Leadership is an international, peer-reviewed, open access journal focusing on leadership for the health profession. The journal is committed to the rapid publication of research focusing on but not limited to: Healthcare policy and law;Theoretical and practical aspects healthcare delivery; Interactions between healthcare and society and evidence-based practices; Interdisciplinary decision-making;

Submit your manuscript here: https://www.dovepress.com/journal-of-healthcare-leadership-journal
Philosophical and ethical issues; Hazard management; Research and opinion for health leadership; Leadership assessment. The manuscript management system is completely online and includes a very quick and fair peer-review system. Visit http://www.dovepress.com/ testimonials.php to read real quotes from published authors. 